\title{
Souvenirs d'une année à Marienbad: documentário de filmagem
}

\author{
Sônia Maria Oliveira da Silva*
}

Resumo: Este artigo analisa Souvenirs d'une année à Marienbad, filme da atriz Françoise Spira durante as filmagens de $O$ ano passado em Marienbad, de Alain Resnais, detendo-se no processo por meio do qual essas imagens, inicialmente despretensiosas, transformaram-se em um vigoroso documentário, material que testemunha um modo específico de fazer cinema no contexto dos anos da Nouvelle Vague.

Palavras-chave: documentário; making of; O Ano passado em Marienbad; Resnais; Spira.

Resumen: Ese artículo analiza Souvenirs d'une année à Marienbad, película de la actriz Françoise Spira durante las grabaciones de El año pasado en Marienbad, de Alain Resnais, deteniéndose en el proceso por el cual esas imágenes, inicialmente sencillas y sin grandes pretensiones, se transforman en un vigoroso documental, en un material que testimonia un modo específico de hacer cine en el contexto de los años Nouvelle Vague.

Palabras clave: documental; making of; El año pasado en Marienbad; Resnais; Spira.

\begin{abstract}
This article discusses Souvenirs d'une année à Marienbad, a film by the actress Françoise Spira during the shooting of Last year in Marienbad, by Alain Resnais. I put emphases on the process by which these images originally disinterested became a powerful documentary, a true witness of a specific mode of making cinema during the Nouvelle Vague.

Keywords: documentary; making of; Last year in Marienbad; Resnais; Spira.
\end{abstract}

Résumé : Cet article analyse Souvenirs d'une année à Marienbad, film réalisé par la comédienne Françoise Spira pendant le tournage de L'année dernière à Marienbad, d'Alain Resnais, en mettant l'accent sur le processus au moyen duquel ces images, à l'origine désintéressées, deviennent un vigoureux documentaire, un témoignage d'un

* Doutora pela Université de la Sorbonne Nouvelle (Paris III), vice-líder do Grupo de Pesquisa Cinema e Comunicação da Universidade Federal de São Carlos (UFSCar), Programa de Pós-Graduação em Imagem e Som - PPGIS, Departamento de Imagem e Som. 13565-905; São Carlos (SP); Brasil.. E-mail: soniaoliveir@yahoo.fr

Este artigo comenta dados extraídos da pesquisa de pós-doutoramento "A encenação de Alain Resnais: estudo dos documentos do processo de criação de O Ano passado em Marienbad"que realizei entre 2010 e 2012 no PPGIS-UFSCar, com supervisão da Profa. Dra. Josette Monzani e apoio da FAPESP.

Sumissão do artigo: 07 de abril de 2016. Notificação de aceitação: 3 de junho de 2016. 
mode spécifique de faire du cinéma dans le contexte de l'ensemble des productions des années de la Nouvelle Vague.

Mots-clés : documentaire ; making of ; L’année dernière à Marienbad ; Resnais; Spira.

Sentada sobre um praticável instalado num jardim, uma jovem sorri, fala e gesticula para a câmera. Num evidente diálogo com quem a filma, ela reúne e agita os dois punhos cerrados, como a indicar resistência, bravura. Estamos no outono de 1960, na Baviera, a poucos quilômetros de Munique. Essas imagens foram captadas durante as filmagens de O Ano passado em Marienbad (1960), de Alain Resnais, no jardim do Castelo de Schleissheim, uma das cinco locações externas do filme ${ }^{1}$, por uma das coadjuvantes do elenco, a atriz Françoise Spira, a moça que sorri no plano acima citado.

A imagem tremula e deixa aparecer também as marcas do tempo: o material permanecera esquecido durante quase 50 anos - ao que se sabe - no porão da casa da sorridente atriz. A câmera que a filma, uma super- 8 , lhe pertence e foi cedida na sequência acima evocada a um(a) do(a)s colegas para que a incluísse nas images. Morta em 1965, ela não chegou a retomar as seis bobinas resultantes de sua filmagem, encontradas apenas em 2008. Entregue ao Institut Mémoires de l'Édition Contemporaine (IMEC), que conserva o conjunto de arquivos do escritor Alain Robbe-Grillet, roteirista de Marienbad ${ }^{2}$, o material foi tratado e os danos provocados pela inadequada acomodação a que esteve submetido durante todos esses anos, reparados.

A indeterminação da temporalidade e da espacialidade das imagens encontradas gerou o apelo a uma legibilidade que seria remediada por um áudio de caráter elucidativo. Porque estariam "rigorosamente ininteligíveis" (Lévy, 2010), as imagens foram submetidas a uma certa "ordem e sentido" (Ibidem) do cineasta alemão Volker Schlöndorff, que integrava a equipe de assistentes de direção de Alain Resnais em Marienbad, ao lado de Jean Léon ${ }^{3}$ (primeiro assistente) e de Florence Malraux.

De Bernard-Henri Levy a Olivier Corpet, todos os que escreveram sobre Souvenirs d'une année à Marienbad, título dado ao documento, referem-se a

1. As filmagens de $O$ Ano passado em Marienbad foram feitas entre 12 de setembro e 21 de novembro de 1960, totalizando 59 dias distribuídos em pouco mais de dez semanas. A primeira fase, feita em locação real, aconteceu em diferentes castelos ou palácios de estilo barroco, situados a poucos quilômetros de Munique: Palácio Münchner Residenz (sequências do corredor, da galeria e do hall), Castelo de Nimphenburg (sequências do jardim noturno terraço, balaustrada e lago), Castelo de Amalienburg (sequências em salão espelhado e demais salas de jogos), Castelo de Schleissheim (teatro, corredores, corredores duplos, escadaria, salão de danças, de tiro, alamedas e banco no jardim e sala de concerto).

2. A partir daqui, utilizaremos essa forma reduzida para referirmo-nos ao filme.

3. Léon foi primeiro-assistente de direção em diversos filmes de Resnais. 
este como making of. Na prática, ele é de fato um. Talvez dos mais legítimos pois feito sem encomenda, no calor dos acontecimentos e por um dos participantes do evento, distinto portanto dos making of comerciais das grandes produções e que visam principalmente à promoção do produto.

Para além de um provável efeito de marketing que possa suscitar a denominação de making $o f^{4}$, o fato é que essas imagens de Spira são um documento eloquente de uma das etapas do processo de criação de um dos mais importantes filmes dos anos 1960. Constitui, na prática, um documentário sobre a filmagem de Marienbad e mostra essencialmente a preparação para a captação das sequências exteriores, nos jardins dos Castelos de Nymphenburg e de Amalienburg, e dos interiores (corredores, abóbadas e salões), no Castelo de Schleissheim e no Münchner Residenz. Além desse cenário natural da Baviera, há também registros de alguns planos feitos no estúdio Photonosor, em Courbevoie, região parisiense (planos do quarto e continuidade dos corredores).

Embora feito despretensiosamente, esse material conquista grande importância no contexto de análise dos processos de criação do filme porque é revelador de um ponto de vista interno à equipe naquilo que se refere ao trabalho dos atores, relativamente alheio porém ao roteiro e inteiramente a parte das diretrizes para a estética almejada no longa.

\section{Da legibilidade das imagens - memória e narração off}

Segundo o filósofo Bernard-Henri Lévy - um dos entusiastas do processo de recuperação das fitas e finalização do documentário - "as imagens em preto e branco e [...] sem som (perfeitamente indecifráveis, então, para qualquer um que não estivesse lá, presente, no set) reimpõem-se a [Schlöndorff] com a força e o frescor do primeiro dia." (Lévy, 2010).

Ao visualizarmos esse documento, percebemos um "texto" feito em sincronia com o desfilamento das imagens, seguindo o desencadeamento de um fluxo de memória no qual informações sobre o processo de filmagem sobrepõem-se à subjetividade do narrador. À época com apenas 21 anos, Schlöndorff é, surpreendentemente, um dos que têm o ar mais grave nas imagens de Spira, como ele mesmo observa. Tem-se então uma sorte de documentário clássico, de 46 minutos, narrado por uma voz off que busca resgatar para as imagens -

4. O filme foi exibido pela primeira vez em dez episódios no site La règle du Jeu, em fevereiro de 2010, em seguida (1\%/3/2010), para convidados, no museu Jeu de Paume, em Paris e depois em Nova Iorque. No verão de 2011, o canal franco-alemão Arte, por ocasião dos 50 anos de $O$ Ano passado em Marienbad, também exibiu o documentário. Mais recentemente, o filme foi disponibilizado no site La règle du jeu, com as versões francesa e inglesa do off de Volker Schlöndorff. 
às vezes desfocadas, trêmulas, hesitantes, às vezes incisivas - algo que esteve presente no momento de sua captura e que possa elucidar aspectos da filmagem de Marienbad.

A narração de Volker Schlöndorff procura atribuir ao material um formato making of na medida em que enfatiza a filmagem do longa. É importante, porém, observar o cuidado tomado ao manipular as informações relacionadas ao filme de Resnais de que dispõe durante a edição, inexistentes no momento da filmagem de Spira. Nesse contexto, o diretor alemão, repetidas vezes alude à atitude de incerteza, de dúvida e de "espera que um mistério passe" reinante no ambiente. É que ali estava-se diante de um processo de fabricação de imagens bastante específicas, se considerarmos as indicações do roteiro de RobbeGrillet para os contrastes da imagem, as poses dos atores, os enquadramentos. Não se pode, nesse contexto, falar por exemplo em criação de personagem propriamente dita, uma vez que o roteiro de $O$ Ano passado em Marienbad exige o abandono ${ }^{5}$ das componentes psicológicas que tradicionalmente embasam a elaboração de um papel (Robbe-Grillet, 1960).

O texto criado por Schlöndorff - feito em poucas horas e envolto num estado febril, segundo conta Bernard-Henri Lévy (Ibidem) - sublinha em primeiro lugar aquilo que é informação: sobre a paciência do diretor, sobre as câmeras, a equipe (relembra os respectivos nomes, papéis interpretados ou funções desempenhadas o cenário dos castelos e sobre o desafio de resistir ao frio daquele outono alemão, com dias especialmente curtos e nos quais a luz natural era escassa.

Detém-se, por exemplo, nos planos que mostram os ensaios da sequência da sala de espelhos e os artifícios para impedir que a câmera neles se refletisse. Segundo conta, a sequência foi preparada durante dois dias e meio, o que permitiu concluir sua filmagem em apenas duas horas. Recém-saído de Zazie dans le métro (1960), de Louis Malle, sua primeira experiência profissional como assistente de direção, e nas quais predominava a improvisação, Schlöndorff encontra em Resnais o procedimento oposto: o ensaio e a preparação.

Surge uma aparente contradição nessa afirmação do diretor alemão se confrontada a outras nas quais atesta a ausência de intervenção de Alain Resnais na criação dos personagens. De fato, o trabalho com os demais atores foi assaz limitado no que diz respeito a atuação uma vez que o próprio roteiro, como já afirmamos, solicitava o apagamento dos traços de caracterização das personagens. Havia, em contrapartida, a exigência de uma marcação precisa de

5. Como pôde ser constatado no exame das diferentes versões do roteiro de Alain RobbeGrillet, depositadas no IMEC (Institut Mémoires de l'Édition Contemporaine). 
gestos e poses do trio de atores principal, extensível aos de papeis secundários, determinados pela constante presença nas cenas e/ou pela concessão de falas.

A atriz Delphine Seyrig, recém-saída do Actors Studio e ávida por composições naturalistas, pôde porém beneficiar-se de forma sistemática de um trabalho de direção por meio do qual foram definidos os traços de sua personagem, criados segundo o Método Strasberg/Stanislavski, no qual incluem-se a criação de um passado e um futuro da personagem ${ }^{6}$, de ações determinantes da sua trajetória até chegar à situação atual e de seus hábitos, entre outros aspectos.

Grosso modo, a narração de Schlöndorff procura situar o espectador contemporâneo quanto à espacialidade das imagens captadas por Spira. Nela organizam-se dois blocos: um primeiro, composto pelo registro da filmagem de Resnais dos planos exteriores, feitos no Castelo de Schleissheim e de Nymphenburg, e um segundo bloco, que agrupa as sequências internas de Marienbad rodadas em Schleissheim, Residenz e Amalienburg e em estúdios, na região parisiense.

A composição do texto para essa polarização fora-dentro foi feita a partir do que Schlöndorff conservou na própria memória, num processo associativo que vai dos elementos técnicos (luz, câmeras, dispositivos) à atmosfera de descontração das filmagens. Percebe-se que ele seguiu então o mesmo batimento de Spira (voltaremos a esse aspecto mais adiante) e que procura atribuir palavras a essas imagens de um episódio do próprio passado, que agora revisita.

Nesse processo de rememoração, tem pouca importância o fato de a memória vacilar e por na abertura de Souvenirs d'une année à Marienbad imagens que considera serem o registro do primeiro dia de filmagem do longa quando na verdade trata-se do $14^{\circ}$. O que é fundamental perceber aqui é que a montagem do documentário priorizou essa sequência - sequência $n^{\circ} 149$ (Baudrot, 1960: paginação irregular) - porque, para Schlöndorff, essa é a "cena principal do filme" de Resnais.

Sobre atribuir "palavras" às imagens, Georges Didi-Huberman postula que nós olhamos para as imagens com palavras mas para que se dê a nomeação é necessário uma poética, que seja composta "uma possibilidade de aproximarse com palavras desse território da imagem que escapa ao discurso" (DidiHuberman, 2011: 87) . É, pois, necessário que as palavras deem abertura

6. A respeito da composição minuciosa da personagem para Marienbad, conferir Delphine Seyrig in Jacqueline Veuve, Delphine Seyrig - portrait d'une comète, Aquarius Film, Suisse. Além, disso, as anotações no seu exemplar de roteiro evidenciam a pesquisa de construção da personagem feita pela atriz.

7. O primeiro dia de filmagem foi feito no Castelo de Nimphenburg e nele foram rodados principalmente os planos das personagens protagonistas (interpretadas por Delphine Seyrig e por Giorgio Albertazzi) atravessando o jardim. 
àquilo que irrompe na estrutura. Essa abertura alinha-se à noção benjaminiana de montagem (Walter Benjamin, 1993: p. 474) que, por sua vez, não é alheia ao sentido cinematográfico do procedimento.

Isso ocorre com a narração de Schlöndorff não nos momentos em que evoca a "vertigem", que seria, segundo ele, o tema do filme de Resnais. Nem quando se questiona sobre o quanto se pode ser tão sério em tão tenra idade. Tampouco está no plano colorido em que ele, já em 2009, exibe na versão do documentário mostrado pelo Canal Arte, o lenço no qual Seyrig deixou-lhe um autógrafo com um beijo de batom. Surge de modo delicado, humano, numa pontuação que expressa a marca do hoje cineasta Schlöndorff - cuja filmografia gira em torno da barbárie nazista e dos campos de concentração, nos quais se incluem O Tambor (1979), O Nono dia (2004) e Diplomatie (2014) -; nessa montagem do dehors-dedans por ele articulada.

Na imagem, Luce Garcia-Ville e Sacha Pitoëff - respectivamente, atriz coadjuvante e segundo protagonista masculino, no elenco de Marienbad ${ }^{8}$ passeiam com um cão. Michèle Manceaux, jornalista do L'Express, também integra a pequena caravana nessa escapada aos entornos de Schleissheim num domingo, dia de folga, portanto. O grupo visita a cidade de Dachau. Schlöndorff começa por sublinhar a trajetória da família Pitoëff, russos que migraram para a França, e sua importância para contexto teatral francês de então. Provavelmente porque as correlações existentes entre a ausência de precisões quanto às características das personagens do roteiro de Alain Robbe-Grillet e das do romance tenham sido apontadas em conversas, Schlöndorff lembra que fora Pitoëff quem lhe "apresentou" O homem sem qualidades (Musil, 1930/43).

Vai-se tecendo assim um novo elo em sua cadeia rememorativa, interrompida ao deparar-se com a ausência de imagens ou outra referência direta ao $K Z$ Dachau, primeiro campo de concentração criado pelos nazistas, a poucos quilômetros dali. Em vez disso, tem-se a filmagem da Octoberfest local. A jornalista presente, conta o narrador, teria tentado entrevistar alguns moradores sobre a proximidade do campo mas estes estariam mais interessados no leilão da quermesse. Apenas 15 anos separam esse episódio do fim da Segunda Guerra.

Essa suposta "digressão" do filme de Spira, um passeio durante a pausa do domingo, acaba por ancorar de certo modo $O$ Ano passado em Marienbad e, consequentemente, o próprio documentário da filmagem, numa temporalidade histórica. A contiguidade da locação do filme de Resnais aos dispositivos da indústria do horror montada pelos nazistas é, evidentemente, fortuita. A esco-

8. Baudrot, S. (1960). Plano de Trabalho (Arquivos do Fonds Sylvette Baudrot), paginação irregular. 
lha da Baviera foi motivada pela grande concentração de que dispõe de castelos no estilo barroco, uma escolha estética de Resnais para Marienbad. É, porém, notável que o comentário off de Schlöndorff, como se corrigisse o enquadramento das imagens de Spira, traga para o centro da imagem exatamente aquilo que ficou de fora.

As imagens dos habitantes de Dachau com os trajes do folclore bávaro ganham assim nova dimensão pelas palavras de Schlöndorff. Reenquadradas, as imagens incluem agora aquilo que estava extra-campo. Mais que isso, diante da força do seu comentário, as imagens da quermesse deixam de ser o registro de um fato anódino. Ao evocar a proximidade do campo de concentração e contrapor essa informação à festa dos habitantes e à beleza arquitetônica das fachadas do vilarejo, ostentadas na tela, Schlöndorff relança a questão da responsabilidade. Vai mais além, evocando também o risco de esquecer-se que o horror aí se fez na sua forma mais abjeta, a alguns quilômetros de um vilarejo para férias, "por trás de uma paisagem tranquila", como asserta o texto de Jean Cayrol no documentário Nuit et Brouillard (1958), de Alain Resnais.

A câmera de Spira não rodou em KZ Dachau. Schlöndorff não pôde porém esquecer a visita, feita antes da ida à quermesse: "Eu me lembro exatamente do [céu] cinza que [havia]. Nós acabávamos de sair do campo, e não conseguíamos compreender a normalidade e até mesmo a beleza da cidade bem perto de Dachau Camp" (Schlöndorff apud Spira, 1960/2010).

\section{Da intimidade ao documentário}

É curioso observar como o filme de Spira, que parece visar inicialmente os tempos mortos que pontuaram as atividades do elenco, a camaradagem entre seus integrantes, acaba por tornar-se, cinco décadas depois, um atestado contundente de um momento importante da História do cinema. Paralelamente às informações contidas no off de Schlöndorff, o documento torna visível as "coxias" de um processo de criação, registrando a mise en acte de artifícios para solucionar os desafios impostos pela estética buscada em Marienbad.

Surgem assim dois pontos de vista que teriam orientado o "olhar" da atriz/ realizadora, ainda que isso muito certamente não tenha sido pré-estabelecido por ela: de um lado, uma proximidade ao registrar as brincadeiras e os momentos de descontração dos atores coadjuvantes e figurantes do elenco, nas quais se incluem também, por vezes, os intérpretes principais - Delphine Seyrig, Giorgio Albertazzi e Sacha Pitoëff - e os técnicos; de outro, uma posição distanciada ao registrar a interação entre Resnais e os técnicos empenhados em solucionar entraves para a composição exigida nas precisas indicações do roteiro. 
Chama nossa atenção, nesse contexto, o fato de que a câmera de Spira oscila entre uma postura de documentarista - quando registra diretamente a filmagem de Resnais, há uma intrínseca suposição de um espectador posterior para quem ela "ofertaria" uma realidade - e uma postura equiparável àquela do realizador de "filme de família", na medida em que filma aquilo que the é próximo, o grupo de atores do qual ela é participante, atitude que ignora o olhar de um espectador a posteriori.

Equipe técnica e elenco do filme de Resnais tornam-se assim "personagens" do filme de Spira e, dada a intimidade com que são mostrados e estimulados a posar para a câmera, acabam por compor o verdadeiro objeto das imagens documentadas: a descontração que animou a equipe, contraposta à complexidade ${ }^{9}$ da narrativa do longa metragem em processo.

O "confinamento" nos castelos da Baviera, esse espaço outro, não-cotidiano, "familiarizaria" a equipe. A existência de um objetivo comum nessa empreitada exigia entusiasmo, como indicia a imagem citada mais acima na qual Spira gesticula para câmera; essa energia equipar-se-ia àquela que sistematicamente anima o realizador do filme de família. As câmeras portáteis, então recém-chegadas ao mercado, eram uma espécie de brinquedo e não seria exagero supor que a empolgação da atriz viria em parte do próprio fato de estar filmando. Ao entrar no quadro, os sujeitos filmados fazem, invariavelmente, uma brincadeira ou direcionam algum comentário para quem detém a câmera. $\mathrm{O}$ riso é constante. Do que riem os indivíduos filmados por Spira? Num primeiro momento, acreditamos, eles não riem "de" nada. Eles riem "com" a própria Spira.

Esse brincar de cineasta seria a primeira causa do riso que acompanha os "personagens" em quase todos os planos. Riem com Spira porque são surpreendidos pela atriz/realizadora na intimidade. Enquanto atores do elenco do filme de Resnais, são "flagrados" na cotidianeidade do gesto, na pausa para um café ou um cigarro, no afago a um amigo. A exemplo do que ocorre no filme de família, os sujeitos filmados aqui também estão circunscritos à ordem da intimidade. A Spira distribuem sorrisos. Florence Malraux, primeira assistente de direção, em meio a uma conversa, percebe-se "olhada" e prossegue o diálogo sem que a timidez seja inteiramente disfarçada. Philippe Brun, cine-

9. Embora, cabe ressaltar, essa complexidade seja questionável se considerarmos a obra do ponto de vista de seus autores - roteirista e realizador. É que, a despeito do resultado final de Marienbad, seus criadores buscavam "jogar" com um conjunto de referência sem estabelecer uma tese específica ainda que fizessem prevalecer a tendência psicológica (Resnais) ou almejavam, de forma lúdica, embaralhar as cartas, entrecruzar fronteiras, construir uma mise en abyme da narrativa (Robbe-Grillet). A densidade narrativa comumente evocada pelo espectador de Marienbad decorre de uma atitude espectatorial de quem não entra no jogo, de quem busca organizar aquilo que intrínsecamente escapa à ordem, foge dos esquemas lineares e que foi construído com esse intuito. 
grafista, também é afetado por esse olhar da câmera, que capta mais uma das vítimas do frio outonal de 1960 às voltas com uma coriza.

Se "para o amador, o cinema é uma foto que se mexe ${ }^{10 "}$ (Kuyper, 1995: 14), o sistemático precipitar-se dos indivíduos filmados para o movimento é, por sua vez, feito quase sempre pela via cômica e/ou pela atestação de um contentamento com o cotidiano. É o peso da objetiva sobre o sujeito, o desconforto do enquadramento ao qual está submetido, bem como a inerente autorepresentação desse "plano" ao qual se terá acesso a posteriori, que o impele a movimentar-se: na busca para preencher o vazio, recorre-se à máscara do sorriso, à tirada, ao gesto engraçado. Há ainda, e antes de tudo, o constante estímulo de quem está por trás da câmera, que pede, exige o movimento.

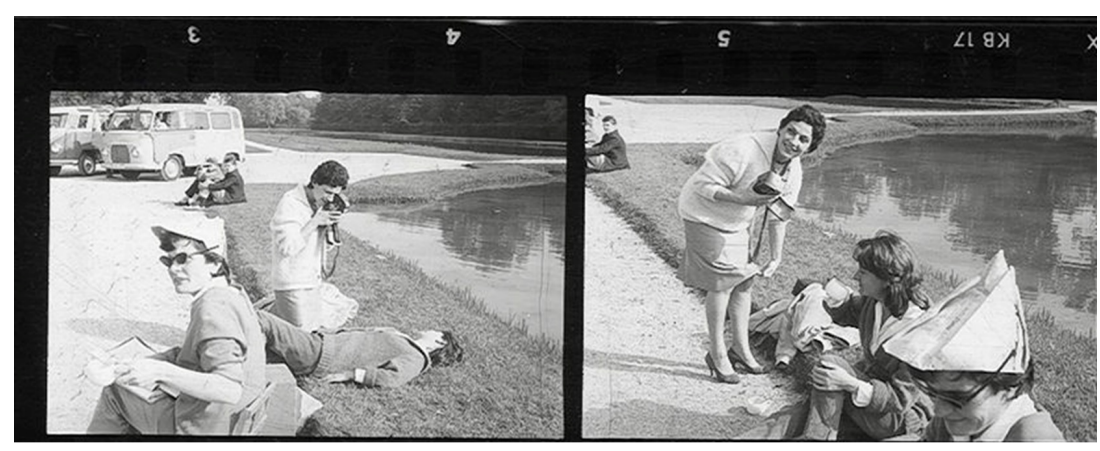

Figura 1. Françoise Spira filma Malraux (centro). S. Baudrot (à esq.) Figura 2. F. Spira, F. Malraux e Silvette Baudrot.

Fonte: Arquivos Sylvette Baudrot (Cinemathèque Française). Fotos: Pierre Guilbaud (Fotogramas de Folha de Contato).

A câmera passa assim de um dos protagonistas masculinos de $O$ Ano passado em Marienbad, o ator italiano Giorgio Albertazzi, que enquanto conversa com a figurante Héléna Kornel tenta arrumar-lhe o cabelo, aos cisnes que estão em torno do lago de Schleissheim para, subitamente, enquadrar uma queda d'água. Esses planos escapam à lógica dos anteriores, inaugurando uma nova conexão, a dos cartões postais que costuma compor o cineasta amador quando

10. Essa perspectiva do cinema como uma fotografia que se movimenta aparece - numa discussão distinta daquela do cineasta amador, evidentemente - aliás nas indicações dadas nas versões originais do roteiro de Alain Robbe-Grillet para Marienbad. A imobilidade dos atores, a rigidez da postura, decorre dessa estética almejada pelo escritor, ganhando porém em Resnais novos contornos. Robbe-Grillet executará esse jogo, o do "batimento" entre a fotografia e o cinema, em L'immortelle (1966), seu primeiro longa metragem. No início do filme, uma mulher (interpretada por Françoise Brion), imóvel olha para a câmera e, até que pestaneje sutilmente, tudo leva a crer que trata-se de uma fotografia. 
registra suas viagens. Aqui, há uma vontade estética, um desejo de incluir algo que teria sido, no momento de sua captura, belo.

Esses elementos serão retomados por Spira posteriormente em diversas ocasiões. Florence Malraux em primeiro plano, sentada à beira do lago num enquadramento que permite ver a queda d'água e os cisnes ao fundo. Fica claro a busca por uma composição da imagem, a escolha e a inserção de uma "personagem" no quadro bucólico. Albertazzi reaparece com uma câmera fotográfica. Ele enquadra Spira, ela o filma. Corte para o ator conversando com Delphine Seyrig, protagonista do filme de Resnais, que saltita para aquecer-se. Volta-se novamente para os cisnes que são então flagrados saindo do lago por uma borda quebrada da mureta.

Françoise Spira filma para resistir ao tédio das horas mortas. Enquanto espera para entrar em cena, mergulha numa flânerie campestre captando cisnes que abandonam lago, flores que brotam entre as pedras, a tentativa frustrada do voo de um pássaro ou a imagem sombria de uma faixa de telhado emoldurada por uma janela aberta. Diversas vezes, a atriz aparecerá nas imagens, revelando que a câmera circulou por outras mãos. Percebe-se também que uma segunda câmera portátil - cuja propriedade desconhecemos - circulava no set já que nas imagens de Spira sobre a fase dos estúdios de $O$ Ano passado em Marienbad vê-se Delphine Seyrig trazendo também uma super-8.

No momento em que registra, Spira é ela mesma, Françoise, a colega de elenco mas também a amiga, tendo em vista a proximidade pré-existente entre alguns integrantes do grupo ${ }^{11}$. Pela recorrência das brincadeiras diante da objetiva, os filmados não parecem considerar que o que está-se fazendo ali é a documentação de um trabalho. Pelo contrário, são as "horas felizes", o momento de descontração, da pausa, do não-trabalho que serão, principalmente, registrados.

À vontade como num filme de família, os sujeitos filmados por Spira agem como se estivessem em casa, na companhia de próximos, logo sendo vistos por um olhar que é igualmente interno. Dito de outro modo, assim como ocorre no filme de família, no momento em que estão sendo fabricadas, não existe um espectador futuro estranho à essa dimensão; a função do espectador, como uma alteridade possível, aí não existe ${ }^{12}$.

11. Os atores Luce Garcia-Ville e Sacha Pitoëff casar-se-iam tempos depois, assim como o diretor Alain Resnais e sua segunda assistente, Florence Malraux.

12. Ainda que essa forte interação entre filmador e filmado, excludente portanto de um espectador posterior, predomine na gênese do filme de família, talvez devêssemos nos perguntar se não haveria um inalienável "vulto" de espectador presumido, daí a recorrência ao sorriso, às brincadeiras, à máscara do contentamento, um desejo de "aparecer bem na foto". 
Sacha Vierny improvisa um olhar sedutor e dá umas piscadelas para a câmera. O diretor de fotografia simula uma discrição no gesto, como se buscasse manter esse jogo apenas entre ele e quem o filma. Há algo de intencionalmente fake tanto no gesto como na aparente intenção de escondê-lo. Insere-se também numa lógica de faz-de-conta o plano em que Sacha Pitoëff faz uma careta para a câmera, brincadeira, aliás, repetida por outros participantes ao longo do filme de Spira.

Além desse tipo de postura fabricada intencionalmente para a lente, que pode ser classsificada como cena, há os "flagrantes" capturados, instantes nos quais quem brinca não sabe que está sendo filmado. É o que se percebe no plano em que a continuísta Sylvette Baudrot ${ }^{13}$ aproxima-se de Resnais e passa, ao que parece, a representar algo: enquadrada de costas, ela dá alguns passos para trás e em, seguida avança, caminhando curvada enquanto narra um história qualquer para o grupo. Todos riem.

Delineia-se na imagem uma dimensão do prazer do aqui-e-agora. Prazer que talvez decorresse de uma atitude voluntária de auto-estímulo contra a sombra do tédio que rondava os artistas, consequência possível das horas de espera. Hoje, diante das imagens de Souvenirs d'une année en Marienbad, ao detectarmos esse aspecto do prazer, identificamos uma correlação com os "signos flagrantes de felicidade" (Kuyper, op. cit.: 15) que habitualmente caracterizam o filme de família, instantes que resultam principalmente da interação entre quem filma e quem é filmado. Seria, no dizer de Kuyper, exatamente essa troca entre os dois participantes do processo de realização do filme de família que resultaria no clima de felicidade que o determina: "havia felicidade porque havia comunicação, partilha " (Ibidem: 16).

Nas imagens de Spira, essa aura de felicidade, essas "interações euforizantes" (Odin, 1995: 50) também são eloquentes, surgindo dissociadas dos comentários de Schlöndorff, ainda que ele próprio venha a sublinhá-las. E há aqui, acima de tudo, a exemplo do que também costuma ocorrer nos filmes de família, o recorrente olhar em direção à câmera, não para fixar o espectador virtual mas para interagir com quem manipula o aparelho.

É exatamente o reiterado contentamento que se vê na tela que leva aquilo que é evocado na narração a deslocar-se do centro da imagem e acomodar-se nas bordas do quadro, abrindo simultaneamente para uma outra história, a das trocas cotidianas. É desse modo que o documento captado por Françoise Spira gira em torno de um objeto incorrigivelmente imaterial. Ocorre que, paradoxalmente, esse foco posto sobre os tempos mortos da filmagem ou, de outro

13. Sylvette Baudrot manteve uma longa colaboração com Alain Resnais tendo sido responsável pela continuidade de grande parte dos filmes do diretor. 
modo, dessa coleção de instantes vazios, tempo não-produtivo de que é feita a vida mesma, ganhou com o passar do tempo outro valor. A exemplo do que pode vir a ocorrer com filmes de família cujas imagens, com o tempo, passam de testemunho de uma intimidade - a da vida de uma família - a um fragmento de "memória coletiva" (Op cit.: 13), aqui também essas imagens sobre um cotidiano - o da filmagem - atingem um outro estatuto, o de documento histórico.

Enquanto tal, primeiramente, dão a ver o modo de trabalho de um dos representantes da "branche" Rive Gauche da Nouvelle Vague, no qual se incluem longo processo de preparação, utilização de estúdios e de roteiros literários escritos por romancistas, peculiaridades que distanciam Resnais dessa escola artística (Marie, 2005: 65). Tendem pois a confirmar que a costumeira inserção de Alain Resnais nesse grupo é antes de tudo uma consequência de sua proximidade a diretores como Agnès Varda e Chris Marker do que efetivamente uma conformidade à estética que o define.

Souvenirs d'une année à Marienbad revela um aspecto intangível do processo de criação em cinema daquele contexto. O que retorna nessas imagens (Didi-Huberman, 2011: 95) feitas por Spira é uma espécie de pacto selado entre o grupo e uma galeria de personagens, obras e autores que então haviam sido trabalhados com vistas a embasar os processos criativos para o longa metragem em curso. Robert Musil, Marcel l'Herbier, Sartre, Pabst, Ibsen, Jensen, Tcheckov... Elas retornam então de Ulrich, Line Hamelin, Loulou, Rebekka, Gradiva, Olga-Macha-Irina, de Frantz. Pelo que têm de jardim, dos ares de aristocracia que emanam dos sujeitos vestidos do figurino de Marienbad, do deslocamento do grupo que vai da cidade para esse hors-contexte das paisagens bucólicas dos jardins dos Castelos da Baviera, as imagens de Spira retornam também de Une partie de Campagne (1936), de Jean Renoir.

Retornam portanto de uma tradição - literária, mas não somente -, na medida em que se inspiram de uma coleção de personagens e autores externos ao processo de fabricação da obra em curso, Marienbad, reafirmando a especificidade de seu diretor no contexto da Nouvelle Vague. Esse vínculo com uma linhagem estética de personagens social e psicologicamente bem constituídos surge nas brechas das imagens captadas por Spira, cujo olhar foi determinado pelo mesmo contexto. A numerosa equipe de Marienbad é formada por profissionais, o elenco é composto por atores provenientes em sua maioria do teatro, o universo é essencialmente o da ficção e o roteiro literário, nessa fase do processo, já está devidamente aferrolhado (Thomas, 1989: 25) - como é 
próprio a Resnais - numa decupagem ${ }^{14}$ minuciosamente preparada que não deixa espaço para improvisações ou inserções ${ }^{15}$ durante a filmagem. Aqui, está-se portanto nas antípodas do estilo determinado pelo grupo Cahiers $d u$ Cinéma, no qual se inserem improvisações, ruptura da fronteira entre ficção e documentário, equipe técnica reduzida, elenco formado por não-atores e baixo orçamento (Marie, op cit: 64-5).

Confrontadas às diferentes versões do roteiro que pudemos consultar, essa imagens reafirmam também a distância existente entre o que Resnais almejava para seu filme e aquilo que pretendia o roteirista, uma nova imagem, sem precedentes, uma não-história, a pura apresentação de personagens sem passado, presente ou futuro, apenas uma imagem refletida na tela.

Se a câmera de Spira "flana" entre seus pares, os integrantes do elenco de apoio, assume porém uma outra postura quando enquadra a filmagem (ou ensaios dela) propriamente dita, ou quando mostra Resnais e seus assistentes reunidos em torno de um aparelho. Nesses momentos, há uma mudança de atitude e um claro indício de busca de objetividade: estabelece-se aí uma lógica do campo/contracampo. É o que pode ser verificado na sequência em que Resnais examina um ângulo para uma determinada tomada e imediatamente vê-se o que estaria sendo enquadrado pela Mitchell, o teto de Schleissheim. Aqui, há um relato objetivado da filmagem, uma posição de narrador(a) que é automaticamente assumida, uma câmera que procura "explicar" o que está sendo feito.

Se as imagens de Spira "divagam" sobre a rachadura da parede do lago do jardim de Schleissheim ou sobre os cisnes na água, retoma o eixo, de quando em vez, para mostrar a superfície interna das abóbadas dos castelos - tão importantes nas imagens de Resnais -, os embates dos técnicos com os dispositivos e a discreta concentração do diretor na preparação da atriz principal.

Nesse contexto, vê-se principalmente as correções do posicionamento das câmeras (Mitchell e Cameflex) e a medição da luz para $O$ Ano passado em Marienbad, assim como a preparação das sequências mais complexas, como a que a personagem de Delphine Seyrig erra pelos "labirintos" do jardim, e para a qual foi instalada uma placa de compensado por onde deslizaria a câmera,

14. Documento utilizado na filmagem resultante do tratamento feito sobre o roteiro literário que consiste em recortar as ações da narrativa em planos e/ou sequências. Sobre emprego do termo e especificidade do documento, ver Burch, N. (1969). Praxis du cinéma. Essai, Paris: Gallimard, p. 11.

15. A estrita obediência à decupagem tornou-se método em Resnais conforme foi-se constituindo sua filmografia de ficção. No caso de Marienbad, modificações e/ou inserções de fragmentos de diálogos foram relativamente constantes. O texto em off relacionado à estátua do jardim é um dos exemplos, tendo sido escrito por Robbe-Grillet e gravado por Giorgio Albertazzi na fase da montagem. 
evitando assim a trepidação que o cascalho poderia ocasionar. Nessa linha percorrida por Spira, incluem-se também os diversos planos de Resnais com os principais integrantes de sua equipe técnica: os assistentes de direção Jean Léon e Florence Malraux, o cinegrafista Philippe Brun e o diretor de fotografia Sacha Vierny, cuja colaboração com Resnais iria se prolongar ao longo dos anos.

Entre planos nos quais domina a descontração do elenco e aqueles nos quais os técnicos improvisam uma dolly, um movimento prevalece: o do surgimento de uma modernidade. Uma modernidade cinematográfica que é feita porém sem ruptura, que compõe com a tradição - da literatura, da pintura, da escultura. Sem que se parta de gestos radicais, como gostaria Robbe-Grillet, é exatamente o movimento de montagem, de composição, e a sobreposição das formas que prevalecerão e que serão determinantes na então nascente filmografia do ficcionista Resnais. É para essa realidade que abre o documentário de filmagem captado por Spira e finalizado por Volker Schlöndorff.

\section{Referências Bibliográficas}

Brody, R. (2010). Last Year, Last Nigth. La Règle du Jeu. Disponível em: http://laregledujeu.org/2010/05/28/1713/last-year-last-night/. Consultado em 24/05/2015.

Benjamin, W. (1993). Paris, capitale du XIXe siècle. Le livre des passages (1927-1940). Paris : Le Cerf.

Burch, N. (1969). Praxis du cinéma: Essai. Paris: Gallimard.

Corpet, O. (2010). Making of de L'Année dernière à Marienbad. La Règle du Jeu. Disponível em: http://laregledujeu.org/2010/07/23/2446/making-ofde-lannee-derniere-a-marienbad-2/. Consultado em 5/01/2011.

Didi-Huberman, G. (2011). La condition des images. In F. Lambert, L'expérience des images. Paris: Ina.

Didi-Huberman, G. (2010). Remontages du temps subi. L'oeil de l'Histoire, 2. Paris: Les éditions de minuit.

Didi-Huberman, G. (2000). Devant le temps. Paris: Les Éditions de minuit.

Kuyper, É. (1995). Aux origines du cinema. In R. Odin (org.), Le film de famille. Usage privé. Usage public. Paris: Meridiens Klincksieck.

Lévy, B.-H. (2010). À new York, le dernier fantôme de Marienbad. Bernard Henri-Levy. La Règle du Jeu. Disponível em: http://www.lepoint.fr/edi tos-du-point/bernard-henri-levy/a-new-york-le-dernier-fantome-de-marie nbad-27-05-2010-459794_69.php. Consultado em 25/05/2015. 
Marie, M. (2005). Nouvelle Vague - Une école artistique. Paris: Armand Colin.

Odin, R. (2000). La question de l'amateur. In R. Odin, Le cinema en amateur. Paris: Communications.

Odin, R. (1995). Le film de famille. Usage privé. Usage public. Paris: Meridiens Klincksieck.

Pinel, V. (2005). Vocabulaire Technique du cinéma. Paris: Armand Colin.

Thomas, F. (1989). L'atelier d'Alain Resnais. Paris: Flammarion.

\section{Filmografia}

Diplomatie (2014), de Volker Schlöndorff.

O Nono dia (2004), de Volker Schlöndorff.

Souvenirs d'une année à Marienbad (1960/2010), de Françoise Spira.

O Tambor (1979), de Volker Schlöndorff.

L'Immortelle (1966), de Alain Robbe-Grillet.

L'Année dernière à Marienbad (1961), de Alain Resnais.

Zazie dans le métro (1960), de Louis Malle.

Nuit et Brouillard (1958), de Alain Resnais.

Une partie de Campagne (1936), de Jean Renoir.

\section{Documentos de Arquivos}

Fonds Robbe-Grillet. "L'Année dernière à Marienbad: scénario, manuscrit." (1/2). Tomo I .(Institut Mémoires de l'Édition Contemporaine - Imec), Caen, 1960.

Fonds Robbe-Grillet. "L'Année dernière à marienbad: découpage, dactylographie. Rélié.'(Institut Mémoires de l'Édition Contemporaine - Imec), Caen, 1960.

Fonds Sylvette Baudrot. Plano de Trabalho. SBG 215-B76-1960. Paris: Bibliothèque du Film. Documento datilografado. Paginação irregular. 